\title{
Nanoparticulate media for environmental applications
}

\author{
Z.Jia, M.Bouslama, M.Ben Amar, M.Amamra, \\ M.Kayser, M.Traore, S.Tieng, K.Chhor, \\ A.Chianese*, V.Nadtochenko , A.Kanaev
Laboratoire des Sciences des Procedes et des Materiaux, CNRS, Universite Paris 13, Sorbonne Paris Cite, France
"Department of Ingegneria Chimica Materiali Ambiente, Sapienza University of Rome, 18 via Eudossiana, 00184 Rome, Italy
Institute of Chemical Physics, Russian Academy of Sciences, 4 Kosygina str., 119991 Moscow, Russia

\section{Received October 30, 2013}

The fabrication of non-agglomerated nanoparticulate solids with an open structure is a challenging task in the field of nanotechnology and nanomaterials. Such solids would permit conserving specific size-selected physical and chemical properties and highest specific area of the active phase, by avoiding severe health problems related to undesirably nanoparticles inhalation. We report on a successful preparation of $\mathrm{Fe}-\mathrm{TiO}_{2}$ and $\mathrm{Ag}, \mathrm{Au}-\mathrm{TiO}_{2}$ coatings and $\mathrm{TiO}_{2}-\mathrm{AlO}_{3}$ ultra-porous monoliths with highly reproducible nanoscale morphology for applications in environmental catalysis.

Получение материалов с открытой структурой на основе неагрегированных наночастиц является актуальной задачей в области нанотехнологий и наноматериалов. Для таких материалов характерной особенностью является сохранение специфических свойств, присущих наночастицам, и высокой удельной поверхности активной фазы при отсутствии негативного влияния на человека продуктов фрагментации материала при их вдыхании. В работе обобщены результаты исследований, связанных с разработкой технологии получения покрытий на основе наночастиц $\mathrm{Fe}-\mathrm{TiO}_{2}$ и $\mathrm{Ag}, \mathrm{Au}-\mathrm{TiO}_{2}$, а также ультрапористых монолитов $\mathrm{TiO}_{2}-\mathrm{Al}_{2} \mathrm{O}_{3}$ с высоковоспроизводимой на наноуровне морфологией. Разработанные материалы являются перспективными для использования в фото- и плазменном катализе.

Наноструктуровані середовища для захисту довкілля. З.Жіа, М.Бен-Алар, М.Алалра, М.Кайзер, М.Траоре, С.Тіенг, К.Шоор, А.Чіанезе, В.Надточенко, А.Канаєв.

Отримання матеріалів з відкритою структурою на основі неагрегованих наночастинок є актуальною задачею у галузі нанотехнологій і наноматеріалів. Для таких матеріалів характерною особливістю є збереження специфічних властивостей, притаманним наночастинкам, та високої питомої поверхні активної фази за відсутності негативного впливу на людину продуктів фрагментації матеріалу при їх вдиханні. У роботі узагальнено результати досліджень пов'язаних 3 розробкою технології отримання покриттів на основі наночастинок $\mathrm{Fe}-\mathrm{TiO}_{2}$ i $\mathrm{Ag}, \mathrm{Au}-\mathrm{TiO}_{2}$, а також ультрапористих монолітів $\mathrm{TiO}_{2}-$ $\mathrm{Al}_{2} \mathrm{O}_{3} 3$ високовідтворною на нанорівні морфологією. Розроблені матеріали $є$ перспективними для використання у фото- та плазмовому каталізі. 


\section{Introduction}

The research on efficient photocatalysts takes part of most hot topics of environmental protection. In this context, titanium dioxide $\left(\mathrm{TiO}_{2}\right)$ solids are of permanent interest [1-3]. Their optimal structural composition is discussed after the synthesis of mixed-phase P25 $\mathrm{TiO}_{2}$ powder, which is widely used as the reference in photocatalytic tests. Attempts to understand and improve its activity are under way [4-6]. However, the results are contraversary and agreement about the best material phase composition is not yet achieved. Besides of the material nature and composition, the nanoscale morphology attracts much attention. A small size and narrow polydispersity of the particles are suggested to be important requirements to the photocatalyst efficiency [7]. This improvement of the photocatalytic activity can be explained by inhibition of the photoinduced charges recombination [8], large specific area of nanoparticles and reactive $\{001\}$ facet exposition [9].

Noble metals deposition improves charge separation in $\mathrm{TiO}_{2}$ and enhances its photocatalyst efficiency [10]. Recently, $\mathrm{Ag}$ and $\mathrm{Au}$ nanoparticles became of a strong scientific interest because of their singular electronic and optical properties governed by surface plasmons [11]. Propositions for the photocatalytic application of the plasmonic systems were made in order to sensibilise $\mathrm{TiO}_{2}$ catalysts in the visible spectral range $[12,13]$. The morphology of substrates plays an essential role in the control of the nucleation-growth process of plasmonic particles and is therefore of importance.

The nanoparticles approach is an efficient solution towards realisation of photocatalysts with controlled nanoscale morphology. In fact, recent studies have shown that this approach permits homogeneous titania doping by avoiding dopant clustering $[14,15]$, impregnation of porous matrixes without pores closure [16-18]. Most recently, silver nanoparticles growth onto monolayer $\mathrm{TiO}_{2}$ nanoparticulate coatings were demonstrated [19]. This method results in a stable reproducible morphology of the prepared coatings, which show high activity in plasma-activated catalytic decomposition of gaseous pollutants [20]. The last process can perform in ambient atmosphere conditions with ultrarapid rise time. Combining non-thermal plasma with heterogeneous catalysis can significantly reduce ener- getic depenses of the gaseous pollutants abbatment.

The proposed method of the material preparation is based on size-selected titanium oxo-alkoxy (TOA) nanoparticles nucleation in the sol-gel reactor with rapid micromixing [21,22]. Although static T-mixers are often employed to achieve the turbulent regime with high Reynolds numbers $R e>10^{3}$, spinning disk reactors present also an efficient solution [23]. After the nucleation, these highly reactive TOA nanoparticles can be stabilized in controlled environmental conditions. In the same time, they are available for chemical doping and immobilisation on hydrophilic substrates. In the present publication we report on the elaboration of several $\mathrm{TiO}_{2}$-based nanoparticulate materials for applications in environmental photo- and plasma-activated catalytic process.

\section{2. $\mathrm{Fe}-\mathrm{TiO}_{2}$ coatings}

The doping of titania solids is one of traditional methods to improve the photocatalytic activity, which consists in introduction of impurities capable to attract one type of the photogenerated charges and thus reducing the probability of the charges recombination. The non-homogeneity of the dopant repartition may result in clustering, which is a major problem to overcome in order to optimize the material efficiency. The non-homogeneity, related to both solubility limit and doping process kinetics, explains e.g. large disagreements in the reported activities of $\mathrm{Fe}-\mathrm{TiO}_{2}$ photocatalysts prepared by different methods (see in [15]).

The homogeneous insertion of $\mathrm{Fe}$ in a titania matrix at the stage of the nanoparticles nucleation of sol-gel process has been realized by Tieng et al. [14]. The method consists in a generation of size-selected TOA nanoparticles following by the reactive colloid deposition onto an appropriate support and thermal treatment in order to achieve the most photocatalitically active crystalline anatase. The TOA nanoparticles binding is excellent to hydrophilic supports, which assures mechanical stability of the photocatalytic media.

Despite of the fact that Fe atoms attract both types of charges $\left(\mathrm{e}^{-}\right.$and $\left.\mathrm{h}^{+}\right)$, their different mobilities result in the optimum doping of 0.005 at. $\%$ explained by a competition between the VB-hole localization on $\mathrm{Fe}^{3+}$ and its annihilation on $\mathrm{Fe}^{2+}$. Based on the proposed charges localization model, our earlier studies have suggested an optimal 
Table 1. Experimental conditions of the $\mathrm{Fe}-\mathrm{TiO}_{2}$ photocatalyst test

\begin{tabular}{||c|c|c|c|c||}
\hline \hline Flow rate & Photocatalyst length & Ethylene concentration & Relative humidity & Pollutant residence time \\
\hline $140 \mathrm{l} / \mathrm{min}$ & $10 \mathrm{~cm}$ & $15 \mathrm{ppm}$ & $28 \%$ & $0.5 \mathrm{~s}$ \\
\hline
\end{tabular}

size of the anatase $\mathrm{TiO}_{2}$ photocatalyst about $8 \mathrm{~nm}$, which is in agreement with available literature data. The optimal $\mathrm{Fe}-\mathrm{TiO}_{2}$ photocatalysts appears to be $\sim 50 \%$ more efficient compared to the pure titania. In the same time, no comparison with the reference P25 Degussa $\mathrm{TiO}_{2}$ catalyst was done. We complete this point in the present study.

The experiments were carried out with the continuous-flow fixed-bed gas-phase photocatalytic reactor described previously [24]. The reactor volume is a glass tube of $6 \mathrm{~mm}$ diameter, which can be filled by glass spheres covered with photocatalyst at the lengths up to $29 \mathrm{~cm}$. This volume is illuminated by 6 UVA lamps $(8 \mathrm{~W})$ emitted at $365 \pm 15 \mathrm{~nm}$. The experimental conditions are listed in Table 1 . The optimal catalyst was prepared with 0.005 wt. $\%$ doping of 5-nm TOA nanoparticles deposited on glass spheres of $1 \mathrm{~mm}$ diameter and thermally treated at $350^{\circ} \mathrm{C}$ during $4 \mathrm{~h}$ in order to obtain pure anatase phase, as confirmed by XRD analysis. The coated spheres by P25 $\mathrm{TiO}_{2}$ were prepared by deep coating from the 2-propanol suspension. The pollutant conversion yield expressed by its inlet $C_{i n}$ and outlet $C_{\text {out }}$ concentrations: $\eta=1-C_{\text {out }} / C_{\text {in }}$ is presented in Fig. 1 as a function of time.

The observed process kinetics is characterized by transient and stationary stages of the conversion yield. The first one can be explained by an accumulation of by-products on the photocatalyst surface; its analysis is beyond the scope of the present article and will be reported elsewhere. We analyze here exclusively the stationary stage. Our results indicated no photocatalyst deactivation at the process duration over a week.

A comparison of the photocatalytic activities of different materials can be performed based on normalization of the photocatalytic reaction rate $R$ on rate of the photoinduced charges generation $d N / d t$, related to the light absorbance: $R=\varepsilon \cdot d N / d t$. In this way, the intrinsic material efficiency $\varepsilon$ due to the photoinduced charges conversion to chemical reactions can be obtained. The rate of the electron-hole pair's generation in the photocatalyst at the lamp illumination is expressed:

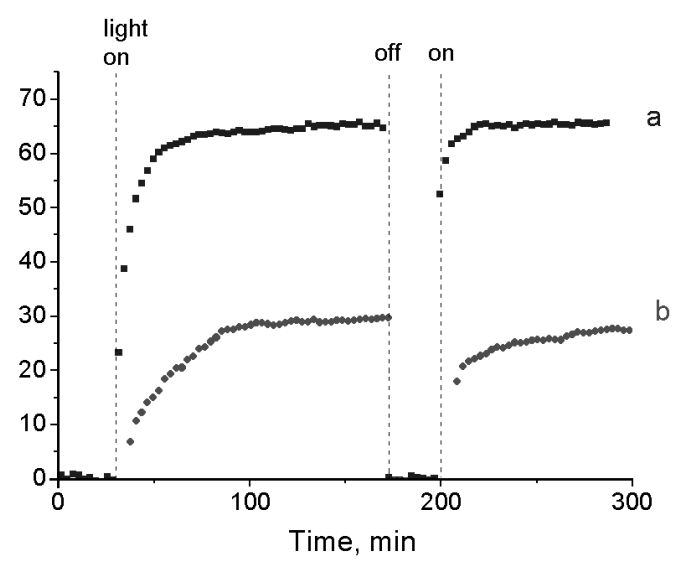

Fig. 1. Ethylene conversion yield using optimal $\mathrm{Fe}-\mathrm{TiO}_{2}$ (a) and reference $\mathrm{TiO}_{2} \mathrm{P} 25$ (b) photocatalysts.

$$
\frac{d N}{d t} \equiv \dot{N}_{t}=a \frac{k_{a b s}}{k_{a b s}+k_{s c a t t}} I_{0}
$$

where $k_{a b s}$ and $k_{\text {scatt }}$ are respectively absorption and scattering coefficients, $I_{0}$ is the lamp intensity and $a$ is a proportionality factor. The absorbance of the glass spheres in the UVA spectral range below $340 \mathrm{~nm}$ is negligible and their opacity is explained by the light scattering: $k_{\text {scatt }}=$ $7.0 \mathrm{~cm}^{-1}$. The transmission of the coated spheres is lower due to the nanocoatings absorption. We have measured $k_{a b s}=$ $0.34 \mathrm{~cm}^{-1}<<k_{\text {scatt }}$ in our $\mathrm{Fe}-\mathrm{TiO}_{2}$ nanocoatings, which is due to the small deposited mass of $\sim 7 \cdot 10^{-4} \mathrm{~g}$ per $\mathrm{g}$ of glass spheres. Eq.(1) than results in:

$$
\dot{N}_{\text {tnano }}=a \frac{k_{a b s}}{k_{\text {scatt }}} I_{0}
$$

In case of $\mathrm{P} 25 \mathrm{TiO}_{2}$ coated spheres, the deposited titania mass is about 40 times larger $\left(k_{a b s}>k_{\text {scatt }}\right)$ and Eq.(1) can be reduced to

$$
\dot{N}_{t P 25} \approx a I_{0}
$$

The photocatalytic activity expressed as $R=\ln \left(C_{\text {in }} / C_{\text {out }}\right)=\ln (1 /(1-\eta))$ can be obtained from measurements of $\eta$ presented in Fig. 1. Consequently, based on Eqs. 2 and 3 and our experimental measurements $R_{\text {nano }} / R_{\mathrm{P} 25}=2.9$, the ratio of the intrinsic 

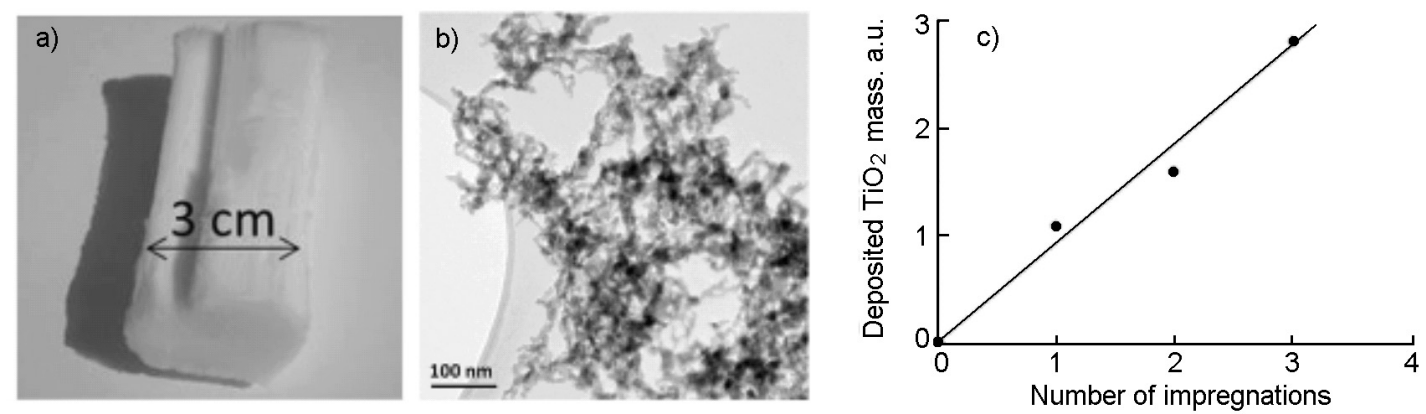

Fig. 2. Photographic (a) and TEM (b) images of $\mathrm{TiO}_{2}-\mathrm{AlO}_{3}$ monolith and deposited titania mass versus number of impregnations (c). The $\mathrm{TiO}_{2}$ nanoparticles are seen as black points in (b).

activities of $\mathrm{Fe}-\mathrm{TiO}_{2}$ and $\mathrm{P} 25 \mathrm{TiO}_{2}$ catalysts can be obtained: $\varepsilon_{\text {nano }} / \varepsilon_{\mathrm{P} 25} \approx 6$. This result shows a clear advantage of using Fe-doped $\mathrm{TiO}_{2}$ nanoparticulate coatings in the photocatalytic process.

\section{3. $\mathrm{TiO}_{2}-\mathrm{AlO}_{3}$ monoliths}

An important problem that limits utilization of single nanoparticles in the photocatalytic process is related to their inherently low absorbance. As a result, the lamps energy is not efficiently transferred to the material and the overall process efficiency is relatively low. An example discussed in Chapter 2 confirms this tendency, showing that despite of the higher intrinsic material activity, the pollutant conversion yield by using $\mathrm{Fe}-\mathrm{TiO}_{2}$ nanocatalyst is smaller than that by using $\mathrm{P} 25 \mathrm{TiO}_{2}$ reference catalyst.

To overcome this shortcoming, adequate supporting materials for nanocatalyst have to be developed. These supports have to be of a high purity (in order to avoid nanoparticles contamination by non-desirably impurities, as e.g. $\mathrm{Na}$ ) and possess evanescent absorption in the UVA spectral range, much smaller than that of the deposited nanoparticles. One potentially interesting material, which satisfies these conditions, is ultraporous alumina (UPA), which can be prepared as bulk monoliths of tens-cm size.

\subsection{Preparation}

The UPA samples with a high porosity $(99 \%)$ and a specific area $\left(\sim 300 \mathrm{~m}^{2} / \mathrm{g}\right)$ were obtained by oxidation of metallic aluminum plates through a liquid mercury-silver layer. The raw product is amorphous consisting of tangled hydrated alumina fibers with a diameter of about $5 \mathrm{~nm}$. The chemical treatment with trimethylethoxysilane (TMES: $\left.\left(\mathrm{CH}_{3}\right)_{3}-\mathrm{Si}-\mathrm{OC}_{2} \mathrm{H}_{5}\right)$ vapor and subsequent thermal treatment at $1300^{\circ} \mathrm{C}$ during $4 \mathrm{~h}$ were used in order to increase their rigidity and mechanical durability. The obtained monoliths (shown in Fig. 2a), are of $\theta$ crystalline phase with surface covered by silica layer of $6 \mathrm{wt} . \%$, conserve their high specific area of $\sim 110 \mathrm{~m}^{2} / \mathrm{g}$.

The photocatalytic media were prepared by impregnation of TOA nanoparticles into the UPA monoliths, which were cut into small pellets of $\sim 2 \mathrm{~mm}$ size. These pellets were introduced into the colloid with reactive metastable TOA nanoparticles, which fills the porous pellets permitting to nanoparticles to react with surface hydroxyls. The pellets are then withdrawn from the reactor and dried overnight at $80^{\circ} \mathrm{C}$. This procedure can be repeated several times in order to increase the loaded titania mass. The loaded catalyst was thermally treated in the temperature range between 400 and $1200^{\circ} \mathrm{C}$ for $4 \mathrm{~h}$, which does not affect the matrix but triggers the $\mathrm{TiO}_{2}$ nanoparticles crystallization into anatase phase.

The TEM image of the impregnated UPA matrix is shown in Fig. 2b. The $\mathrm{TiO}_{2}$ nanoparticles are seen in the fibrous structure as well-dispersed black points. The loaded nanoparticles mass is directly proportional to the number of impregnations, as shown in Fig. 2c. In the present work, the maximum number of three impregnations was employed, which results in the nanoparticles mass loading $~ 30$ wt. $\%$. The nanoparticles aggregation in UPA matrixes is prohibited in these conditions, which leads to the monolithic material with unique response inherent to a single nanoparticle, which functional properties can be tuned.

\subsection{Properties}

The photocatalytic reaction rate of gaseous ethylene decomposition into $\mathrm{H}_{2} \mathrm{O}+$ $\mathrm{CO} / \mathrm{CO}_{2}$ on $\mathrm{TiO}_{2}-\mathrm{AlO}_{3}$ catalyst is shown in Fig. 3 as a function of temperature of the 


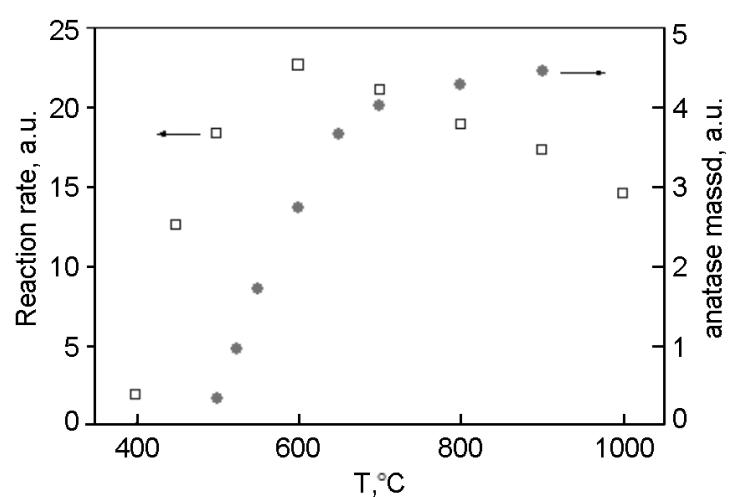

Fig. 3. First-order photocatalytic decomposition rate of ethylene by $\mathrm{TiO}_{2}-\mathrm{AlO}_{3}$ catalyst and mass fraction of anatase $\mathrm{TiO}_{2}$.

TOA nanoparticles treatment. In the same Fig. 3, we plot the mass fraction of the TOA nanoparticles completed amorphousanatase phase transition. Our measurements show that in the temperature range below $1000^{\circ} \mathrm{C}$ the nanoparticles remain $100 \%$ anatase and their size does not significantly change, which confirm their negligible aggregation.

The observed appearance of the amorphous-anatase conversion at $T>500^{\circ} \mathrm{C}$ is characteristic of single $5-\mathrm{nm} \mathrm{TiO}_{2}$ nanoparticles [25]. In the same time, we see that the maximum photocatalytic activity of the photocatalyst is attained after thermal treatment at $600^{\circ} \mathrm{C}$, where the amorphousanatase conversion is not complete and about 25 wt.\% of amorphous titania remains. This fact suggests better photocatalytic activity of a mixed anatase/amorphous composition compared to pure crystalline anatase.

Previously, research of the optimal photocatalyst polymorphism concerned anatase/rutile mixtures, since that was the composition of best reference $\mathrm{P} 25 \mathrm{TiO}_{2}$ photocatalyst, which contains agglomerated crystalline $\mathrm{TiO}_{2}$ particles of $15-30 \mathrm{~nm}$ size of major anatase $(\sim 70 \%)$ and minor rutile (30\%) content [26,27]. The presence of small amount of the amorphous phase is generally underestimated, since the amorphous titania is expected to be inactive [28]. In agreement with Carneiro et al. [6], our results confirm the material activity inhibition by appearance of the rutile phase [18]. In contrast, a presence of the amorphous phase onto anatase nanoparticles seems to enhance the photocatalytic activity.

\section{4. $\mathrm{Ag}-\mathrm{TiO}_{2}$ coatings}

It has been previously shown that the surface roughness plays an essential role in the deposited silver morphology [29], which is of key importance for applications in plasmonics. In particular, upright nanoparticles grow up preferentially on relatively thick $\mathrm{TiO}_{2}$ substrates with surface roughness about $10 \mathrm{~nm}$, while hemispherical and spherical silver nanoparticles are grown on (111) rutile crystalline surface. A considerable photocatalytic activity of TOA nanoparticles permits $\mathrm{Ag}^{+} / \mathrm{Au}^{+}$ions reduction and silver/gold nanoparticles surface growth. The small thickness $(5 \mathrm{~nm})$ and roughness $(0.5 \mathrm{~nm})$ of the TOA nanoparticulate coatings permit highly stable and reproducible nanoscale surface morphology of the metal nanoparticles. In particularly, we have shown that silver nanoparticles form spherical segment with $h / D=1 / 4$ and $D=12 \mathrm{~nm}$ with the total deposited mass approaching $\sim 10^{7}$ at $/ \mu \mathrm{m}^{2}$ at long times [19].

The deposition of $\mathrm{Ag} / \mathrm{Au}$ nanoparticles has been realized by photocatalytic reduction of $\mathrm{Ag}^{+} / \mathrm{Au}^{+}$ions in aqueous solution of $\mathrm{AgNO}_{3} / \mathrm{HAuCl}_{4}$ with 2-propanol addition (in ratio 5:1) as a hole scavenger. The metal ions reduction was carried out by UVA irradiation $\left(6.9 \mathrm{~mW} / \mathrm{cm}^{2}, 360 \pm 10 \mathrm{~nm}\right)$ of the TOA coatings deposited on glass substrates. The irradiation time was varied from 1 to 60 min. After the irradiation cycle, the plate was withdrawn from the solution, washed and dried during $4 \mathrm{~h}$ at $80^{\circ} \mathrm{C}$.

The SEM images of the obtained nanoparticulate $\mathrm{Ag}-\mathrm{TiO}_{2}$ coatings are shown in Fig. 4. The both $\mathrm{Au}$ and Ag coatings show similar morphologies with the metal nanoparticles grown in size and number and process saturation at long irradiation times. In agreement with previous observations of Ag nanoparticles, $\mathrm{Au}$ reduction on rough substrates seemingly produces large particles of rectangular and triangular shapes. In contrast, the growth on smooth surfaces results in much smaller particles of spherical-like shape.

A homogeneous dispersion of metal nanoparticles on substrates can be evidenced by the plasmonic response of these coatings. The fluorescent images of the coatings were measured with excitation by a near-IR Ti:sapphire laser (Spectra Physics), producing $100 \mathrm{fs}$ pulses centered at $800 \mathrm{~nm}$ with repetition rate of $80 \mathrm{MHz}$ and average power up to $\sim 45 \mathrm{~mW}$, coupled with an inverted microscope via apochromatic objec- 

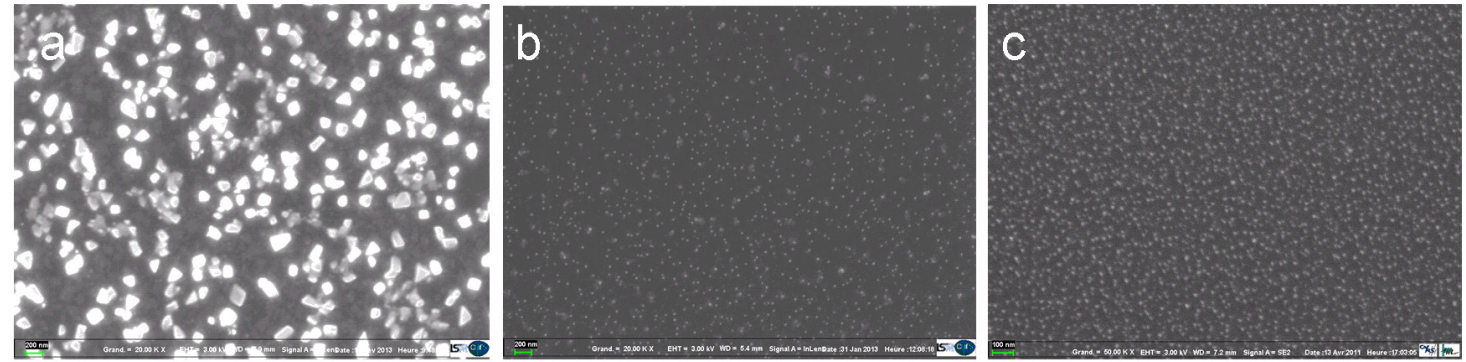

Fig. 4. SEM images of the $\mathrm{Au}-\mathrm{TiO}_{2}$ nanocoatings prepared at $\mathrm{pH}=4$ after 10 (a) and 1 min (b) UVA exposition on rough (a) and smooth (b) glass substrates and of $\mathrm{Ag}-\mathrm{TiO}_{2}$ nanocoatings prepared in neutral $\mathrm{pH}$ conditions after 5 min UVA exposition (c).

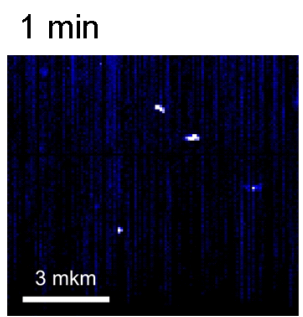

$2 \min$

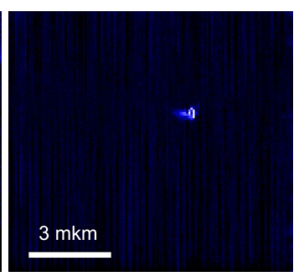

$10 \mathrm{~min}$

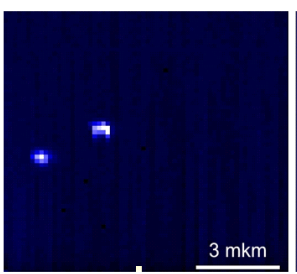

$20 \min$

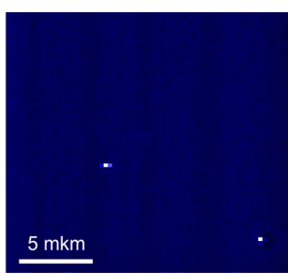

$40 \mathrm{~min}$

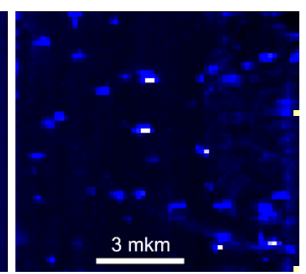

Fig. 5. Image of the luminescence "hot spots" distribution onto the monolayer nanoparticulate titania film after UVA photocatalytic silver reduction during 1, 2, 10, 20 and 40 min.

tive Olympus UPLSAPO 100×NA 1.40. Fig. 5 shows the luminescence "hot spots" enhanced by surface plasmons for different times of the silver reduction process on a monolayer TOA nanoparticulate surface. The field enhancement requires the interparticle distance to be below $10 \mathrm{~nm}$ [30], which seems to be non-preferable geometry in our material morphology for small times of the deposition process ( $t \leq 20 \mathrm{~min})$.

This confirms the homogeneous surface repartition of silver nanoparticles. For longer times $t \geq 40 \mathrm{~min}$, an increase of the "hot spots" number density is observed, which indicates that the interparticle distance attains the critical one enabling the field enhancement. The nanocoatings with high number density of surface plasmon resonances are currently suggested for photocatalytic applications. Since surface plasmons absorb in the visible spectral range, the obtained results permit to consider the nanoparticulate $\mathrm{Ag}, \mathrm{Au}-\mathrm{TiO}_{2}$ coatings for environmental photocatalysis in the visible.

Alternatively, the activation of $\mathrm{Ag}, \mathrm{Au}-$ $\mathrm{TiO}_{2}$ catalysts can be achieved by plasma. Our results indicate that $\mathrm{Ag}-\mathrm{TiO}_{2}$ and $\mathrm{Au}-$ $\mathrm{TiO}_{2}$ coatings consisting of $10 \mathrm{~nm}$ size spatially separated metal nanoparticles possess high and comparable activities in the plasma-catalytic process of gaseous acetaldehyde $\left(\mathrm{CH}_{3} \mathrm{CHO}\right)$ pollutants decomposition [31]. Moreover, the activity of the finest non-agglomerated nanoparticules (Fig. 4b,c) appears to be significantly higher than that of the coarsen particles (Fig. 4a). The morphology of the Ag,Au deposition, which can be stably reproduced on the smooth monolayer nanoparticulate TOA coatings, shows the best performance. The maximum specific efficiency of these nanopartuculate coatings (normalized on catalyst mass) corresponds to the deposition of $\sim 20 \mathrm{ng} / \mathrm{cm}^{2}$ of silver or gold $\left(\sim 10^{6}\right.$ at $\left./ \mu \mathrm{m}^{2}\right)$. Moreover, the gold nanoparticles are most stable against oxidation and show less dangerous by-products and higher $\mathrm{CO}_{2}$ conversion.

\section{Conclusions}

We describe nanoparticulate materials based on $\mathrm{TiO}_{2}$ nanoparticles with a high potential for applications in environmental catalysis. Particular interest is paid to $\mathrm{Fe}-$ $\mathrm{TiO}_{2}$ and plasmonic $\mathrm{Ag}, \mathrm{Au}-\mathrm{TiO}_{2}$ coatings as well as to $\mathrm{TiO}_{2}-\mathrm{AlO}_{3}$ ultraporous monoliths with unique single-nanoparticle response. The nanoparticle approach to the material elaboration permits their homogeneous doping. An example of the $\mathrm{Fe}-\mathrm{TiO}_{2}$ photocatalyst shows that its intrinsic activity signifi- 
cantly higher compared to those of pure $\mathrm{TiO}_{2}$ and reference $\mathrm{P} 25 \mathrm{TiO}_{2}$ samples. The proposed approach to the material fabrication permits highly reproducible nanoscale material morphology and composition, which are of key importance for the reproduction and optimization of functional properties.

Acknowledgments. This work was supported by COST Chemistry Action of the European Commission, French network C'Nano IdF and Excellence laboratory SEAM (France).

\section{References}

1. A.Fujishima, K.Hashimoto, T.Watanabe, $\mathrm{TiO}_{2}$ Photocatalysis: Fundamentals and Applications, BKC, Tokyo (1999).

2. J.-M.Herrmann, Catalysis Today, 53, 115 (1999).

3. K.Hashimoto, H.Irie, A.Fujishima, Jpn.J. Appl. Phys., 44, 8269 (2005).

4. A.Piscopo, D.Robert, J.V.Weber, J.Photochem. Photobiol. A, 139, 253 (2001).

5. D.C.Hurum, A.G.Agrios, K.A.Gray et al., $J$. Phys. Chem. B, 107, 4545 (2003).

6. J.T.Carneiro, T.J.Savenije, J.A.Moulijn, G.Mul, J.Phys.Chem. C, 115, 2211 (2011).

7. J.Marugan, D.Hufschmidt, G.Sagawe et al., Water. Res., 40, 833 (2006).

8. Z.Zhang, C-C.Wang, R.Zakaria, J.Y.Ying, J. Phys. Chem. B, 102, 10871 (1998).

9. G.Liu, C.Sun, H.G.Yang et al., Chem.Commun., 46, 755 (2010).

10. H.Tada, K.Teranishi, Y.Inubushi, S.Ito, Langmuir, 16, 3304 (2000).

11. S.A.Maier, Plasmonics: Fundamentals and Applications, Springer, NY (2007).
12. K.Awazu, M.Fujimaki, C.Rockstuhl et al., J. Am. Chem. Soc., 130, 1676 (2008).

13. S.Linic, P.Christopher, D.B.Ingram, Nature Mater., 10, 911 (2011).

14. S.Tieng, R.Azouani, K.Chhor, A.Kanaev, $J$. Phys. Chem. C, 115, 5244 (2011).

15. S.Tieng, K.Chhor, A.Kanaev, J.Appl.Catal.A, 399, 191 (2011).

16. P.Pucher, M.Benmami, R.Azoauni et al., $J$. Appl.Catal.A, 332, 297 (2007).

17. M.Bouslama, M.C.Amamra, S.Tieng et al., $J$. Appl.Catal.A, 402, 156 (2011).

18. M.Bouslama, M.C.Amamra, Z.Jia et al., ASC Catalysis, 2, 1884 (2012).

19. Z.Jia, M.Ben Amar, A.Astafiev et al., J.Phys. Chem. C, 116, 17239 (2012).

20. Z.Jia, A.Vega-Gonzalez, M.Ben Amar et al., Catalysis Today, 208, 82 (2013).

21. R.Azouani, A.Soloviev, M.Benmami et al., $J$. Phys. Chem. C, 111, 16243 (2007).

22. R.Azouani, A.Michau, K.Hassouni et al., Chem. Eng. Res. Design, 88, 1123 (2010).

23. B.de Caprariis, M.Di Rita, M.Stoller et al., Chem. Eng. Sci., 76, 73 (2012).

24. M.Benmami, K.Chhor, A.Kanaev, Chem.Eng. Trans., 6, 55 (2005).

25. O.Khatim, M.Amamra, K.Chhor et al., Chem. Phys. Lett., 558, 53 (2013).

26. R.I.Bickley, T.Gonzalez-Carreno, J.S.Lees et al., J.Sol.State.Chem., 92, 178 (1991).

27. B.Ohtani, O.O.Prieto-Mahaney, D.Li, R.Abe, J. Photochem. Photobiol. A, 216, 179 (2010).

28. B.Ohtani, Y.Ogawa, S.I.Nishimoto, J.Phys. Chem. B, 101, 3746 (1997).

29. I.Tanabe, K.Matsubara, N.Sakai, T.Tatsuma, J.Phys. Chem. C, 115, 1695 (2011).

30. Yu.V.Barbashov, A.D.Zalesskii, A.V.Aibushev et al., Nanotech.Russia, 6, 668 (2011).

31. Z.Jia, A.Vega-Gonzalez, M.Ben Amar, K.Hassouni, A.Kanaev, X.Duten, to be published. 